\title{
Supraorbital Keyhole Endoscopic Assisted Approach for Excision of Anterior Clinoidal Meningioma
}

\section{Arun Reddy Marathi' ${ }^{*}$, Boyina Jagadeshwar Rajesh ${ }^{2}$ and Kartik Manoj Multani $^{3}$}

${ }^{1}$ Senior Resident, Department of Neurosurgery, Yashoda Hospital, Secunderabad,

India

${ }^{2}$ Senior Consultant, Department of Neurosurgery, Yashoda Hospitals, Secunderabad, India

${ }^{3}$ Resident, Department of Neurosurgery, Yashoda Hospital, Secunderabad, India

*Corresponding Author: Arun Reddy Marathi, Senior Resident, Department of

Neurosurgery, Yashoda Hospital, Secunderabad, India.

DOI: 10.31080/ASNE.2022.05.0486
Received: December 28, 2021

Published: February 22, 2022

(C) All rights are reserved by Arun Reddy

Marathi., et al.

\begin{abstract}
Advances in Neurosurgeon's armamentarium in the form of navigation, high end microscope, rigid endoscope, and intra operative Magnetic resonance imaging (MRI) have encouraged them to develop or modify the surgical technique to minimize the exposure and dissection of normal anatomy of brain. These modifications led to development of "keyhole neurosurgery" which is based on principle of "minimal access" that leads to decreased post operative morbidity and facilitates patient's recovery. Supra orbital keyhole approach through the eyebrow is one such technique to gain access to the anterior skull base. Further combining endoscopic assistance to standard microsurgical techniques improves illumination and vision at depth and reduces collateral damage to nearby brain parenchyma. We share our experience and technique for intoto excision of a right anterior clinoidal meningioma through endoscopic assisted supraorbital keyhole craniotomy and anterior sub frontal approach and conclude it to be a safe, minimally invasive technique for approaching the anterior cranial base lesions as well as approaching the aneurysms of anterior skull base with minimal damage of neighboring normal anatomy. It does involve learning curve to operate though this technique and one must have the conventional approach too in the back of the mind as a standby.
\end{abstract}

Keywords: Supra Orbital Keyhole Approach; Eyebrow Approach; Anterior Skull Base Lesions; Endoscope

\section{Introduction}

There have been numerous procedures developed to approach the anterior skull base. They include frontal, bi frontal, frontotemporal, pterional and orbitozygomatic approaches [1-3]. The evolution started way back from frontotemporal "macrosurgical approach" of Dandy's to Yasargil's microsurgical pterional approach, and finally reached to the minimally invasive approach, one of which is supraorbital keyhole approach through an eyebrow incision [4]. Supraorbital keyhole approach is one of the shortest approaches of dealing with the anterior skull base lesions. The goal of "keyhole" surgery is not to perform a small incision and craniotomy but to permit adequate access to the lesions while limiting collateral trauma to surrounding structures such as the skin, bone, dura, and, most importantly, the brain [5-7].

Surface lesions typically require large craniotomies but deepseated lesions especially the skull base lesions can be accessed through a much smaller craniotomy since the intracranial field widens with increasing distance from the skull, especially with the use of Endoscope [4,5,7-9]. 
When considering any approach, it is important to understand the advantages and disadvantages of a given procedure. Surgery through an eyebrow incision may not be appropriate for all lesions of the anterior skull base. There would be narrow viewing angle and limited exposure of light to the operative field with the use of microscope in deep seated lesions though a small opening $[4,7]$. Rigid endoscope alone or in combination with microscope can be more beneficial in supraorbital approach. The endoscope provides much greater light source and panoramic visualization. Ensuring an enough size to the craniotomy (no smaller than $1.5-2 \mathrm{~cm}$ ) is important for adequate maneuverability of instruments [4,7]. We share our experience of operating a type 2 anterior clinoidal meningioma by transcilliary supraorbital keyhole craniotomy and endoscopic assisted subfrontal approach.

\section{Case Report}

43-year-old man presented with a one-year history of intermittent bitemporal headache without symptoms of raised intracranial pressure or seizures. Clinically he had mild left hemisensory loss. Magnetic resonance imaging (MRI) brain revealed a small right thalamic bleed and type 2 right anterior clinoidal meningioma. He was conservatively managed for the thalamic bleed and reimaged 3 months later which revealed total recovery from the thalamic bleed with presence of right anterior clinoidal meningioma (Figure 1a1e). He then underwent right supraorbital eyebrow approach with microscopic and assisted endoscopic intoto excision of the lesion. Post operatively he had no deficits with good resolution of the surgical scar eventually.

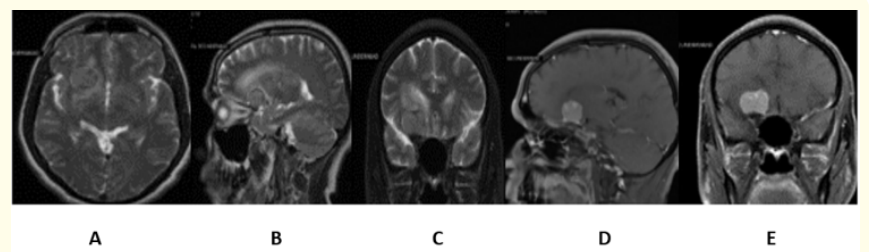

Figure 1: A-E: Preoperative MRI images.

\section{Surgical Technique}

Head was fixed on Mayfield 3 pin skull clamp in supine, with slight elevation and extension by 15 degrees to allow gravity retraction of frontal lobes and turned towards left by 20 degrees. The skin incision given within the right eyebrow starting lateral to supra orbital groove and extending for $4 \mathrm{cms}$ up to the frontal process of zygoma. Incision was deepened till the frontalis muscle, which was incised and elevated along with the periosteum laterally up to the temporalis muscle which was also elevated laterally. Burr hole was made at the site of elevated temporalis muscle and converted into craniotomy of around $2 \times 2.5 \mathrm{cms}$ and orbital rim was drilled flush with skull base. Dura incised with base towards the skull base. With the help of microscope initial survey was done and later endoscope was introduced and cerebrospinal fluid (CSF) was drained from lateral sylvian cistern to create space. Proper care was taken to avoid injury to the basifrontal region. Now only with help of rigid endoscope tumor attachment was coagulated and careful peritumoural dissection was done and tumor was delivered in toto. Proper hemostasis was ensured after making sure there was no insult to the brain parenchyma. Dura was closed watertight. Bone fixed with miniplates. Frontalis and temporalis muscle was sutured. Skin was then closed with subcuticular stitches (Figure 2a-2n). Post op recovery was good and the next day computed tomography (CT) scan revealed gross total excision of lesion (Figure 3a,3b). Three months MRI scan revealed no evidence of lesion (Figure 4). Post-operative day 3 (Figure 5a) and 3 months (Figure 5b) operative scar were cosmetically very good.

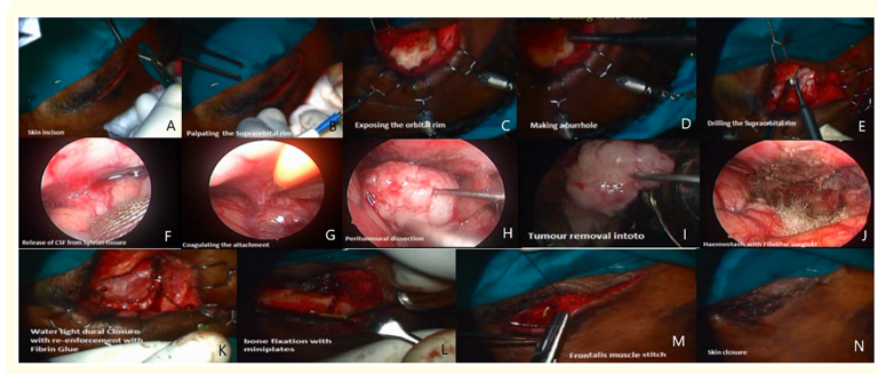

Figure 2: A-N: Description of Operative steps.

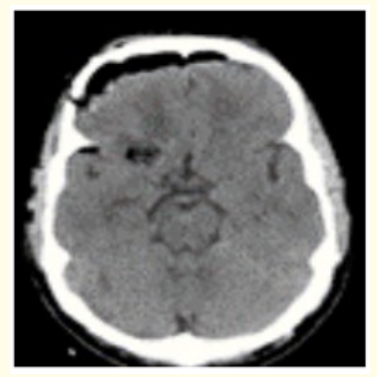

Figure 3: Postoperative day $1 \mathrm{CT}$. 


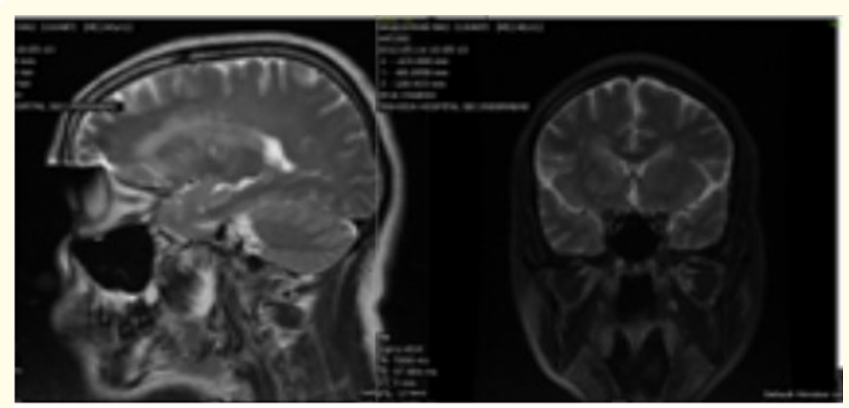

a

$b$

Figure 4: 3 months Post op MRI image.

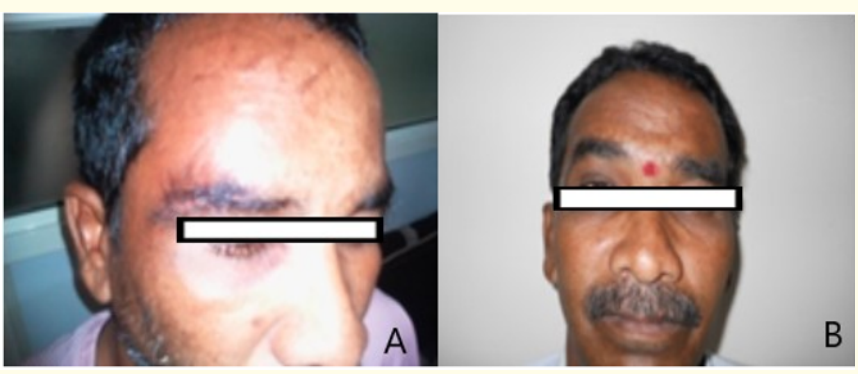

Figure 5: Postoperative day 3- and 3-month postoperative picture showing cosmetic healing of surgical scar.

\section{Discussion}

Supraorbital craniotomy was first demonstrated by Krause [10] on cadavers and eight years later, he operated on a patient with meningioma successfully. When this approach was described through eyebrow, there was significant controversy $[4,7]$. There was a notion that this keyhole approach would limit the access for the surgical field for safe surgery. There were initial concerns for the cosmesis too in the form of bony repair, incision and CSF leaks as well. There were also reports of functional loss of supraorbital nerve or frontalis branch of facial nerves in the early case series [2]. Subsequently this approach was popularized by Pernecsky and coworkers [7]. Later with the advent of rigid endoscope, this approach regained much needed attention. The advances in technology such as neuronavigation, microscope, endoscope, CUSA, drills, glue, bone substitutes have helped in developing the technique to a much safer level with good surgical and functional outputs.
The most important thing in keyhole approach compared to standard microsurgical approach is the working angle and field of vision. With the use of endoscope, there has been improvement in the field of vision and better illumination leading to better surgical outcomes $[3,8]$. The surgeon needs to have a good bimanual technique to avoid cross talk between the instruments. A limited skin incision within the eyebrow, preservation of supraorbital nerve and later good closure of dura and craniotomy site are much needed for better surgical outcomes. If anticipating larger skin incision and a wider craniotomy, it is wiser to plan for bicoronal approach, which can yield better outcome. In the supraorbital craniotomy the opening of bone is small but can remove the larger lesions through piecemeal approach. Hence good selection of cases mandates the use of this approach.

\section{Conclusion}

The fully endoscopic and endoscopic assisted approach through the eyebrow is simple and safe alternative as opposed to conventional surgeries specially for small anterior skull base tumors as well as vascular abnormalities. However, one has to remember the that learning curve is an important factor and should a keep an option for conventional surgery as an emergency standby.

\section{Bibliography}

1. Delashaw JR JB., et al. "Modified supraorbital craniotomy: technical note". Neurosurgery 30 (1992): 954-956.

2. Jho HD. "Orbital roof craniotomy via an eyebrow incision: a simplified anterior skull base approach". Minimally Invasive Neurosurgery 40 (1997): 91-97.

3. Chen HC and Tzaan WC. "Microsurgical supraorbital keyhole approach to the anterior cranial base". Journal of Clinical Neuroscience 17.12 (2010): 1510-1514.

4. Reisch R and Perneczky A. "Ten-year experience with the supraorbital subfrontal approach through an eyebrow skin incision". Neurosurgery 57.4 (2005): 242-253.

5. Perneczky A. "Planning strategies for the suprasellar region: philosophy of approaches". Neurosurgeon 11(1992): 343-348.

6. Perneczky A., et al. "Keyhole Concept in Neurosurgery” (1999). 
7. Reisch R., et al. "Surgical technique of the supraorbital keyhole craniotomy". Surgical Neurology 59.3 (2003): 223-227.

8. Fries G and Perneczky A. "Endoscope-assisted brain surgerypart 2-analysis of 380 procedures". Neurosurgery 42.2 (1998): 226-232.

9. Menovsky T., et al. "Endoscope-assisted supraorbital craniotomy for lesions of the interpeduncular fossa". Neurosurgery 44.1 (1999): 106-112.

10. Krause F. “Chirurgie des Gehirns und Rückenmarks nach eigenen Erfahrungen“. Berlin: Urban and Schwarzenberg (1908).

\section{Assets from publication with us}

- Prompt Acknowledgement after receiving the article

- Thorough Double blinded peer review

- Rapid Publication

- Issue of Publication Certificate

- High visibility of your Published work

Website: www.actascientific.com/

Submit Article: www.actascientific.com/submission.php

Email us: editor@actascientific.com

Contact us: +919182824667 